For submission to Polyhedron

\title{
Directing dimensionality in uranyl malate and copper uranyl malate compounds.
}

\author{
Erica Cole, Erin Flores, Madeline Basile, Ashini Jayasinghe, Joshua de Groot, Daniel K. Unruh,
} Tori Z. Forbes*

\begin{abstract}
Uranyl hybrid compounds are complex materials due to variability in coordination geometry, flexibility in ligand chelation, and metal hydrolysis, which leads to difficulty in controlling the secondary building units. The presence of transition metals in uranyl hybrid materials adds to the complexity, but also leads to an increase in the dimensionality of the topology from infinite chains and 2-D sheets, to 3-D framework lattices. In this study, five uranyl malate compounds were synthesized at room temperature: $\left(\left(\mathrm{C}_{4} \mathrm{H}_{12} \mathrm{~N}_{2}\right)\left[\left(\mathrm{UO}_{2}\right)_{2}\left(\mathrm{C}_{4} \mathrm{H}_{3} \mathrm{O}_{5}\right)_{2}\right]\right.$

- $4 \mathrm{H}_{2} \mathrm{O}$ (UMal1), $\left(\mathrm{C}_{4} \mathrm{H}_{12} \mathrm{~N}_{2}\right)\left[\left(\mathrm{UO}_{2}\right)_{2}\left(\mathrm{C}_{4} \mathrm{H}_{3} \mathrm{O}_{5}\right)_{2}\right]$ (UMal1-b), $\left[\left(\mathrm{UO}_{2}\right)\left(\mathrm{C}_{4} \mathrm{H}_{3} \mathrm{O}_{5}\right) \mathrm{Cu}\left(\mathrm{C}_{10} \mathrm{H}_{8} \mathrm{~N}_{2}\right) \mathrm{Cl}\left(\mathrm{H}_{2} \mathrm{O}\right)\right] \cdot 2 \mathrm{H}_{2} \mathrm{O}$ (UCuMal1), $\left[\left(\mathrm{UO}_{2}\right)_{2}\left(\mathrm{C}_{4} \mathrm{H}_{3} \mathrm{O}_{5}\right)_{2} \mathrm{Cu}\left(\mathrm{C}_{5} \mathrm{H}_{5} \mathrm{~N}\right)_{2}\left(\mathrm{H}_{2} \mathrm{O}\right)_{2}\right] \bullet 2 \mathrm{H}_{2} \mathrm{O}(\mathbf{U C u M a l 2})$, $\left[\left(\mathrm{UO}_{2}\right)_{2}\left(\mathrm{C}_{4} \mathrm{H}_{3} \mathrm{O}_{5}\right)_{2} \mathrm{Cu}\left(\mathrm{C}_{5} \mathrm{H}_{5} \mathrm{~N}\right)_{2}\left(\mathrm{H}_{2} \mathrm{O}\right)_{2}\right] \cdot 2 \mathrm{H}_{2} \mathrm{O}$ (UCuMal3)). These compounds were characterized using single-crystal X-ray diffraction, thermogravimetric analysis and Raman spectroscopy. All five compounds contain an identical uranyl malate secondary building unit that could be further linked through the $\mathrm{Cu}$ (II) cation. In this system, the identity of the ligands bonded to the $\mathrm{Cu}(\mathrm{II})$ cation impacted dimensionality and could be the key to designing materials with a known uranyl building unit.
\end{abstract}




\section{Introduction}

Developing hybrid materials with specific structural connectivity and controlled physical properties is the overall goal of crystal engineering, but in practice, manipulating the individual building units to achieve the overall structural goal can be difficult [1-5]. This is particularly true for complex coordination geometries observed in hexavalent uranium, which forms strong covalent interactions to two $\mathrm{O}$ atoms to create the nearly linear uranyl cation $\left(\mathrm{UO}_{2}\right)^{2+}$ as a fundamental building unit [6-10]. Flexibility for the uranyl moiety occurs with additional coordination about the equatorial plane, resulting three possible geometries: square, pentagonal, or hexagonal bipyramids $[6,9]$. Plasticity in the molecular geometry for the uranyl cation combined with variability in the chelation of the metal center by multidentate organic linkers results in limited predictability in structural features of the individual building units $[7,9]$. An additional design feature to consider in U(VI) hybrid materials is metal hydrolysis, which can further change the coordination of the ligand and provide additional variability of the individual building units $[7,10,11]$.

There are several excellent reviews and journal articles that highlights the crystal engineering principles in uranyl hybrid materials and the difficult nature of controlling the design features for these compounds [7-9, 12-16]. An extensive review by Loiseau et al. [8], focuses on the vast body of literature of uranyl carboxylate materials and highlights the distinct secondary building units that can arise from the carboxylate chelation. This detailed report emphasized the significant number of uranyl carboxylate compounds arising from the ability of the ligand to bond to the uranyl cation in either a mono- or bidentate fashion and form unpredictable extended arrays through free carboxylate oxygen atoms [8, 10]. Andrews and Cahill [7] discuss several 
approaches to structural design in uranyl compounds and focus significant attention to additional supramolecular approaches towards rational design of materials. In both reviews, the importance of metal hydrolysis is noted in the formation oligomers and their contribution to secondary building unit evolution $[7,8]$.

Even with the variability in ligand denticity, chelation, and intramolecular interaction, there is still a propensity of $\mathrm{U}(\mathrm{VI})$ materials to be controlled by the passivation of the uranyl oxo groups,[17] resulting in the formation of 1-D chains and 2-D sheet topologies and limiting extended 3D frameworks $[6,8]$. One strategy to increase dimensionality of uranyl materials is to include a second metal cation, but in creating these heterometallic systems, additional complexity is introduced to the overall design. First-row transition metals and lanthanide cations are the most common secondary metal to be added to uranyl compounds and do result in the formation of a larger fraction of extended 3D networks [8]. This is specifically true for the incorporation of $\mathrm{Cu}(\mathrm{II})$ into hybrid uranyl compounds, where sixteen of the thirty reported structures contain framework topologies [18-30]. In addition, Thuery [31] detailed the importance of the $\mathrm{Cu}(\mathrm{II})$ cation to induce the formation of dodeca- and hexadecanuclear cluster compounds at the expense of more traditional 1- and 2-D topologies. Some variability within the structure is added through the role of the transition metal as either just a charge balancing species in the crystalline lattice or as a linker between the uranyl secondary building units [8]. Additional flexibility is also gained through the presence of the $\mathrm{Cu}(\mathrm{II})$ cation because of variation of coordination geometry; however, important structural design features for controlling dimensionality are still difficult to discern.

Our research group is specifically interested in designing uranyl hybrid materials with macrocyclic and nanotubular features [32], thus understanding the design principles that control 
dimensionality is of great interest. A majority of our work focuses on ligand sterics as the major design principle, but U(VI) nanotubular motifs [33-35] and nanoclusters [31, 36] have been formed using transition metal cations. Herein, we provide the structural and chemical characterization of five uranyl malate structures $\left(\left(\mathrm{C}_{4} \mathrm{H}_{12} \mathrm{~N}_{2}\right)\left[\left(\mathrm{UO}_{2}\right)_{2}\left(\mathrm{C}_{4} \mathrm{H}_{3} \mathrm{O}_{5}\right)_{2}\right] \bullet 4 \mathrm{H}_{2} \mathrm{O}(\mathbf{U M a l 1})\right.$, $\left(\mathrm{C}_{4} \mathrm{H}_{12} \mathrm{~N}_{2}\right)\left[\left(\mathrm{UO}_{2}\right)_{2}\left(\mathrm{C}_{4} \mathrm{H}_{3} \mathrm{O}_{5}\right)_{2}\right]\left(\right.$ UMal1-b), $\left[\left(\mathrm{UO}_{2}\right)\left(\mathrm{C}_{4} \mathrm{H}_{3} \mathrm{O}_{5}\right) \mathrm{Cu}\left(\mathrm{C}_{10} \mathrm{H}_{8} \mathrm{~N}_{2}\right) \mathrm{Cl}\left(\mathrm{H}_{2} \mathrm{O}\right)\right] \cdot 2 \mathrm{H}_{2} \mathrm{O}$ (UCuMal1), $\left[\left(\mathrm{UO}_{2}\right)_{2}\left(\mathrm{C}_{4} \mathrm{H}_{3} \mathrm{O}_{5}\right)_{2} \mathrm{Cu}\left(\mathrm{C}_{5} \mathrm{H}_{5} \mathrm{~N}\right)_{2}\left(\mathrm{H}_{2} \mathrm{O}\right)_{2}\right] \cdot 2 \mathrm{H}_{2} \mathrm{O}$ (UCuMal2), $\left[\left(\mathrm{UO}_{2}\right)_{2}\left(\mathrm{C}_{4} \mathrm{H}_{3} \mathrm{O}_{5}\right)_{2} \mathrm{Cu}\left(\mathrm{C}_{5} \mathrm{H}_{5} \mathrm{~N}\right)_{2}\left(\mathrm{H}_{2} \mathrm{O}\right)_{2}\right] \cdot 2 \mathrm{H}_{2} \mathrm{O}$ (UCuMal3)) and the importance of ligand denticity is discussed in relationship to controlling dimensionality of the overall system.

\section{Experimental}

All solutions were prepared using Millipure water (18.2 M $\Omega$ ) and chemicals purchased were used directly without further purification. CAUTION: $\left(\mathrm{UO}_{2}\right)\left(\mathrm{NO}_{3}\right)_{2} \cdot 6 \mathrm{H}_{2} \mathrm{O}$ contains radioactive ${ }^{238} \mathrm{U}$, which is an alpha emitter, and like all radioactive materials must be handled with care. These experiments were conducted by trained personnel in a licensed research facility with special precautions taken towards the handling, monitoring, and disposal of radioactive materials.

2.1. Synthesis

UMal1 $\left(\mathrm{C}_{4} \mathrm{H}_{12} \mathrm{~N}_{2}\right)\left[\left(\mathrm{UO}_{2}\right)_{2}\left(\mathrm{C}_{4} \mathrm{H}_{3} \mathrm{O}_{5}\right)_{2}\right] \bullet 4 \mathrm{H}_{2} \mathrm{O}$ and UMal1-b $\left(\mathrm{C}_{4} \mathrm{H}_{12} \mathrm{~N}_{2}\right)\left[\left(\mathrm{UO}_{2}\right)_{2}\left(\mathrm{C}_{4} \mathrm{H}_{3} \mathrm{O}_{5}\right)_{2}\right]:$ A solution containing $1 \mathrm{~mL}$ of $0.2 \mathrm{M}$ aqueous uranyl nitrate, one $\mathrm{mL}$ of $0.2 \mathrm{M}$ aqueous nickel chloride and two $\mathrm{mL}$ of $0.2 \mathrm{M}$ aqueous DL-malic $\left(\mathrm{C}_{4} \mathrm{H}_{6} \mathrm{O}_{5}\right)$ acid was prepared and the $\mathrm{pH}$ adjusted to 3.0 by $1.0 \mathrm{M}$ piperazine. A $500 \mu \mathrm{L}$ aliquot of the final solution was then transferred to a two mL glass vial and layered with one mL of toluene. After two weeks, yellow platelets of UMal1 were discovered on the side of the vial. Several crystals 
associated with a minor secondary phase (UMal1-b) were also observed upon further aging and isolated based upon a variations in the morphology (blade versus plate). Multiple reactions produced yields ranging from $20-40 \%$.

UCuMal1 and UCuMal2 $\left[\left(\mathrm{UO}_{2}\right)\left(\mathrm{C}_{4} \mathrm{H}_{3} \mathrm{O}_{5}\right) \mathrm{Cu}\left(\mathrm{C}_{10} \mathrm{H}_{8} \mathrm{~N}_{2}\right) \mathrm{Cl}\left(\mathrm{H}_{2} \mathrm{O}\right)\right] \cdot 2 \mathrm{H}_{2} \mathrm{O}$ : One mL of $0.2 \mathrm{M}$ aqueous uranyl nitrate hexahydrate, one $\mathrm{mL}$ of $0.2 \mathrm{M}$ copper chloride, one $\mathrm{mL}$ of $0.2 \mathrm{M}$ aqueous D,L-malic acid or L-malic acid, and two mL of 0.1 M 2,2-bipyridine that had been dissolved in a 1:1 EtOH: $\mathrm{H}_{2} \mathrm{O}$ solvent mixture were combined in a glass vial. The resulting clear teal solution was stirred for two minutes and the $\mathrm{pH}$ adjusted to 2.11 with $400 \mu \mathrm{L} 1.0 \mathrm{M}$ piperazine. After one week in a sealed vial under ambient conditions, lime green crystals formed on the bottom of the vessel. The crystals were isolated through vacuum filtration with yields of 56 and $82 \%$ for UCuMal1 and UCuMal2, respectively.

UCuMal3 $\left[\left(\mathrm{UO}_{2}\right)_{2}\left(\mathrm{C}_{4} \mathrm{H}_{3} \mathrm{O}_{5}\right)_{2} \mathrm{Cu}\left(\mathrm{C}_{5} \mathrm{H}_{5} \mathrm{~N}\right)_{2}\left(\mathrm{H}_{2} \mathrm{O}\right)_{2}\right] \cdot 2 \mathrm{H}_{2} \mathrm{O}$ : An initial solution containing one $\mathrm{mL}$ $0.2 \mathrm{M}$ aqueous uranyl nitrate hexahydrate and one $\mathrm{mL}$ of $0.2 \mathrm{M}$ aqueous copper chloride was placed in a glass vial and the $\mathrm{pH}$ was adjusted to 3.72 with $150 \mu \mathrm{L}$ pyridine. Two $\mathrm{mL} 0.1 \mathrm{M}$ DL-malic acid was added to the vial and the solution stirred for 20 minutes. At this point a colloidal phase was detected due to the translucent teal color of the liquid, so $550 \mu \mathrm{L} 1.0 \mathrm{M}$ $\mathrm{HNO}_{3}$ was added to the vial and the final solution was transparent. After one week in a sealed vial under ambient conditions, crystals had formed with yields of $35 \%$.

\subsection{Structural Characterization}

In all cases, crystals were taken from the mother liquor, coated in Infinium oil and mounted on a Nonius Kappa CCD single crystal X-ray diffractometer equipped with MoK $\alpha$ radiation $(\lambda=0.7107 \AA)$ and a low temperature cryostat set at $100 \mathrm{~K}$. Data were collected with 
the Nonius Collect software package [37] and peak intensities were corrected for Lorentz, polarization, and background effects using the Bruker APEX II software [38]. An empirical correction for adsorption was applied using the program SADABS within the Bruker Suite of software.[38] The structure solution was determined by direct methods and refined on the basis of $F^{2}$ for all unique data using the SHELXTL version 5 series of programs [39]. The primary sites of $\mathrm{U}, \mathrm{Cu}, \mathrm{O}, \mathrm{C}$, and $\mathrm{N}$ atoms were initially determined by intrinsic phasing with any disordered locations being determined from the difference Fourier maps. Hydrogen atoms associated with organic components were constrained using a riding model, whereas the $\mathrm{H}$ atoms on bound and interstitial water molecules (where possible) were determined from the difference Fourier maps following subsequent least-squares refinement of the partial structure models and restrained using the DFIX and DANG commands.

UMal1 crystallizes in the triclinic space group $P-1$ with $a=7.9421(6) \AA, b=8.4226(6)$ $\AA, c=9.1852(6) \AA, \alpha=75.067(2)^{\circ}, \beta=73.037(2)^{\circ}$, and $\gamma=79.497(2)^{\circ}$. A related compound for UMal1 (UMal1-b) crystallizes in the triclinic space group $P-1$ with $a=7.8529(19) \AA, b=$ 8.2762(19) $\AA, c=8.895(2) \AA, \alpha=106.530(7)^{\circ}, \beta=115.225(7)^{\circ}$, and $\gamma=91.534(7)^{\circ}$. Significant disorder was observed for the UMal and UMal-b structures and the U, O, and C atoms had to be modeled as split sites. For the compound UCuMal1, the U1 is modeled as three partially occupied sites due to positional disorder. Before modeling the partially occupied sites, multiple centro- and noncentrosymetric space groups were investigated. Doubling the unit cell axis in the [100] direction was also attempted to resolve the disorder, but that did not result in significant improvement in the structural model. Similar issues were initially observed for UCuMal2, but higher quality crystals were synthesized, which solved the positional disorder in the crystal. Additional synthesis attempts did not result in improvement in the crystallinity of the UCuMal1 
compound. UCuMal 2 was modeled in the space group $\mathrm{P} 2{ }_{1}$ and additional symmetry within the structure was considered using the ADDSYM function of PLATON,[40] but a center of symmetry could not located. Additional crystallographic information regarding the structural models for the uranyl and copper uranyl compounds can be found in Tables 1. Selected bond distances and angles for each compound can be found in the supporting information section.

Table 1. Selected crystallographic information for $\left(\mathrm{C}_{4} \mathrm{H}_{12} \mathrm{~N}_{2}\right)\left[\left(\mathrm{UO}_{2}\right)_{2}\left(\mathrm{C}_{4} \mathrm{H}_{3} \mathrm{O}_{5}\right)_{2}\right] \bullet 4 \mathrm{H}_{2} \mathrm{O}$ (UMal1), $\left(\mathrm{C}_{4} \mathrm{H}_{12} \mathrm{~N}_{2}\right)\left[\left(\mathrm{UO}_{2}\right)_{2}\left(\mathrm{C}_{4} \mathrm{H}_{3} \mathrm{O}_{5}\right)_{2}\right](\mathbf{U M a l 1 - b}),\left[\left(\mathrm{UO}_{2}\right)\left(\mathrm{C}_{4} \mathrm{H}_{3} \mathrm{O}_{5}\right) \mathrm{Cu}\left(\mathrm{C}_{10} \mathrm{H}_{8} \mathrm{~N}_{2}\right) \mathrm{Cl}\left(\mathrm{H}_{2} \mathrm{O}\right)\right] \bullet 2 \mathrm{H}_{2} \mathrm{O}$ (UCuMal1), $\left[\left(\mathrm{UO}_{2}\right)_{2}\left(\mathrm{C}_{4} \mathrm{H}_{3} \mathrm{O}_{5}\right)_{2} \mathrm{Cu}\left(\mathrm{C}_{5} \mathrm{H}_{5} \mathrm{~N}\right)_{2}\left(\mathrm{H}_{2} \mathrm{O}\right)_{2}\right] \bullet 2 \mathrm{H}_{2} \mathrm{O}$ (UCuMal2), $\left[\left(\mathrm{UO}_{2}\right)_{2}\left(\mathrm{C}_{4} \mathrm{H}_{3} \mathrm{O}_{5}\right)_{2} \mathrm{Cu}\left(\mathrm{C}_{5} \mathrm{H}_{5} \mathrm{~N}\right)_{2}\left(\mathrm{H}_{2} \mathrm{O}\right)_{2}\right] \bullet 2 \mathrm{H}_{2} \mathrm{O}(\mathbf{U C u M a l 3})$

\begin{tabular}{llllll} 
& \multicolumn{1}{c}{ UMal1 } & \multicolumn{1}{c}{ UMal1-b } & \multicolumn{1}{c}{ UCuMal1 } & \multicolumn{1}{c}{ UCuMal2 } & \multicolumn{1}{c}{ UCuMal3 } \\
\hline $\mathrm{FW}(\mathrm{g} / \mathrm{mol})$ & 962.21 & 890.14 & 710.32 & 710.32 & 1095.64 \\
Space Group & $P-1$ & $P-1$ & $P 2_{1} / n$ & $P 2_{1}$ & $P-1$ \\
$a(\AA)$ & $7.9421(6)$ & $7.853(2)$ & $8.2649(9)$ & $8.2614(6)$ & $7.7476(4)$ \\
$b(\AA)$ & $8.4226(6)$ & $8.276(2)$ & $16.9591(18)$ & $16.9977(13)$ & $8.3366(4)$ \\
$c(\AA)$ & $9.1852(6)$ & $8.895(2)$ & $13.9972(15)$ & $14.0497(11)$ & $11.5285(6)$ \\
$\alpha\left({ }^{\circ}\right)$ & $75.067(2)$ & $106.530(7)$ & 90 & 90 & $71.460(2)$ \\
$\beta\left({ }^{\circ}\right)$ & $73.037(2)$ & $115.225(7)$ & $96.735(4)$ & $97.334(3)$ & $80.146(2)$ \\
$\gamma\left({ }^{\circ}\right)$ & $79.497(2)$ & $91.534(7)$ & 90 & 90 & $74.765(2)$ \\
$\mathrm{V}\left(\mathrm{g} / \mathrm{cm}^{3}\right)$ & $564.02(7)$ & $494.0(2)$ & $1948.4(4)$ & $1956.8(3)$ & $678.03(6)$ \\
$\mathrm{Z}$ & 2 & 1 & 4 & 4 & 2 \\
$\rho_{\text {calc }}\left(\mathrm{g} / \mathrm{cm}^{3}\right)$ & 2.810 & 2.61 & 2.422 & 2.391 & 2.684 \\
$\mu\left(\mathrm{mm}^{-1}\right)$ & 14.427 & 16.445 & 9.586 & 9.544 & 12.776 \\
$\mathrm{~F}(000)$ & 432 & 400 & 1332 & 1308 & 503 \\
Crystal size (mm) & $0.18 \times 0.17 \times 0.08$ & $0.17 \times 0.05 \times 0.04$ & $0.20 \times 0.18 \times 0.06$ & $0.20 \times 0.10 \times 0.10$ & $0.20 \times 0.18 \times 0.10$ \\
Theta range $\left(^{\circ}\right)$ & 2.70 to 27.02 & 2.61 to 27.04 & 1.894 to 27.446 & 1.46 to 25.29 & 1.87 to 25.34 \\
Limiting & $-10<h<10$ & $-9<h<9$ & $-10<h<10$ & $-9<h<9$ & $-9<h<9$ \\
Indices & $-10<k<10$ & $-10<k<10$ & $-21<k<21$ & $-20<k<20$ & $-10<k<10$ \\
& $-9<l<11$ & $-11<l<10$ & $-18<l<18$ & $-16<l<16$ & $-13<l<13$ \\
Refl. collect/uniq. & $9545 / 2451$ & $7282 / 2148$ & $33845 / 4449$ & $33959 / 7087$ & $11950 / 2473$ \\
$\mathrm{R}_{\text {int }}$ & 0.0283 & 0.0323 & 0.0243 & 0.0242 & 0.0169 \\
GOF & 1.089 & 1.075 & 1.141 & 1.043 & 1.041 \\
Final R [I $>2 \sigma(\mathrm{I})]$ & $R_{1}=0.0268$, & $R_{1}=0.0198$, & $R_{1}=0.0288$, & $R_{1}=0.0186$, & $R_{1}=0.0140$, \\
& $w R_{2}=0.0704$ & $w R_{2}=0.0451$ & $w R_{2}=0.0638$ & $w R_{2}=0.0434$ & $w R_{2}=0.0369$ \\
Final R (all data) & $R_{1}=0.0276$, & $R_{1}=0.0214$, & $R_{1}=0.0318$, & $R_{1}=0.0197$, & $R_{1}=0.0140$, \\
& $w R_{2}=0.0710$ & $w R_{2}=0.0457$ & $w R_{2}=0.0649$ & $w R_{2}=0.0437$ & $w R_{2}=0.0371$ \\
\hline
\end{tabular}

\subsection{Chemical Characterization}

Powder X-ray diffractograms of bulk crystalline products were collected from 5-60 $2 \theta$ with a step size of 0.05 and a count time of 1 sec/step on a Bruker D-5000 diffractometer $(\mathrm{Cu}$ $\mathrm{K} \alpha$ ) equipped with a LynxEye solid state detector. After determining purity of the samples, 
thermogravimetric analysis of samples were performed using a TA instruments TGA Q500. Approximately 15-20 mg of each sample was placed onto an aluminium pan and heated from 25$600{ }^{\circ} \mathrm{C}$ in air at a ramp rate of $2{ }^{\circ} \mathrm{C} /$ minute. A powder $\mathrm{X}$-ray diffraction pattern was also collected after the heat cycle to determine the identity of the residual product. Raman spectroscopy was performed on single crystal samples using a Nicolet Almega XR High Performance Dispersive spectrometer with a $785 \mathrm{~nm}$ excitation laser.

\section{Results and Discussion}

\section{Structural Characterization}

The common structural feature across all five compounds is dinuclear uranyl malate secondary building unit that forms an extended coordination polymer throughout the crystalline lattice. Each U(VI) cations form two strong bonds with oxygen atoms to create the nearly linear uranyl cation, $\left(\mathrm{UO}_{2}\right)^{2+}$, with average bond length and angle of 1.773(4) $\AA$ and $178.5(2)^{\circ}$, respectively. The uranyl moiety is further coordinated about the equatorial plane by five $\mathrm{O}$ atoms with bond lengths ranging from 2.319(4) - 2.443(4) Å forming a pentagonal bipyramidal coordination geometry about the metal center. Each , malate ligand is fully deprotonated and shared between two U(VI) polyhedra, with the carboxylate end members bonded to separate $\mathrm{UO}_{2}{ }^{2+}$ cations and the deprotonated alcohol group bridging the metal atoms into a dinuclear secondary building unit. Deprotonation of the alcohol upon complexation of the malate ligand to the uranyl cation has been previously observed for coordination complexes and confirmed by NMR spectroscopy [41]. The resulting building block is further linked via the carboxylate functional groups to create a one-dimensional infinite chain topology. 
a)

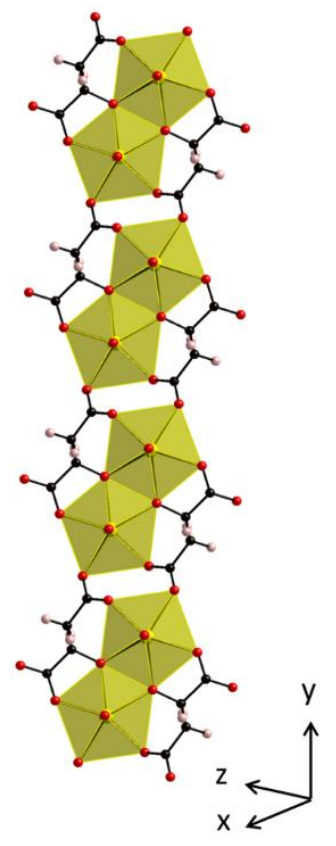

b)

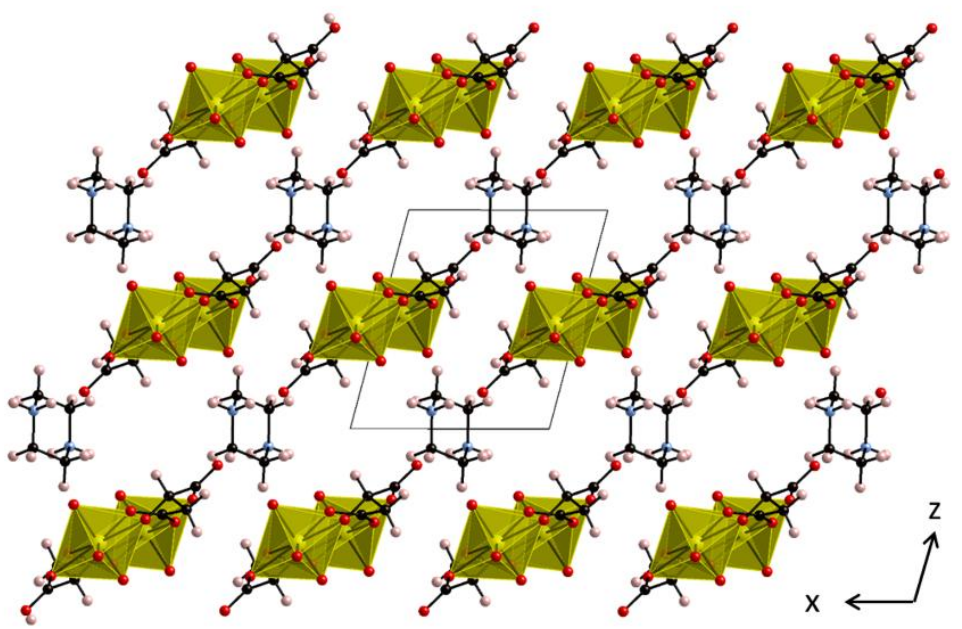

Figure 1. a) Dinuclear uranyl building units in UMal1 and UMal1-b are linked into a chain topology through the malate ligands. b) Piperazinium cations participate in hydrogen bonding interactions with the uranyl malate chains to create the extended crystallographic network. U polyhedra are depicted in yellow and the $\mathrm{O}, \mathrm{C}, \mathrm{N}$, and $\mathrm{H}$ atoms are represented by red, black, light blue and pink sphere, respectively. 
Loiseau et al.[8] determined that the dinuclear secondary building unit is a relatively common motif, with forty-seven structures reported in the literature. A dinuclear secondary building unit composed of two uranyl pentagonal bipyramids with two bridging groups (i.e. a shared edge) is the most common configuration, with twenty-five reported compounds. The identity of the bridging groups has typically been $\mu_{3}-\mathrm{O}$ atoms from the carboxylate group of the ligand or an independent $\mu_{2}-\mathrm{OH}$ group, whereas no $\mu_{2}-\mathrm{O}$ complexes have been reported [8].

UMal1 and UMal1-b also contain an $\mu_{3}-\mathrm{O}$ atom, but instead of the carboxylate functional group it is part of a deprotonated alcohol.

Nine of the twenty-five compounds with the shared edge dinuclear motif also contain polymerization of the secondary building unit into a 1-D chain topology [8, 42-46]. Structures of particular note include $\left[\left(\mathrm{UO}_{2}\right)(\mathrm{HCit})\right]^{-}$and $\left[\left(\mathrm{UO}_{2}\right)(\mathrm{Citml})\right]^{-}(\mathrm{Cit}=$ Citrate, $\mathrm{Citml}=\mathrm{D}$-citramalate $)$ synthesized under hydrothermal conditions and crystalized in the presence of DABCO and bipyridine [43]. Malate belongs in the same family of these ligands, with variation dependent on the substitution of the proton on the central carbon atom by either a methyl or carboxylate group to create the citramalate or citrate molecules, respectively. All three ligands chelate to the uranyl secondary building unit in an identical fashion, with $\mu_{3}-\mathrm{O}$ bridges forming the shared edge and polymerization taking place through free carboxylate $\mathrm{O}$ atoms to form an extend chain topology [43].

In UCuMal1 and UCuMal2, $\mathrm{Cu}(\mathrm{II})$ atoms have been added to the exterior of the uranyl malate chains (Fig. 2). The $\mathrm{Cu}$ (II) cations are complexed in a bidentate fashion to the $\mathrm{N}$ atoms of the bipyridine molecule and bond to the exterior of the uranyl chain via the free carboxylate $\mathrm{O}$ atom of the malate ligand. The first shell coordination about the $\mathrm{Cu}$ (II) cation is completed 
through the interaction of the metal center with one chlorine atom and one water molecule.

Average bond lengths for $\mathrm{Cu}-\mathrm{N}, \mathrm{Cu}-\mathrm{O}, \mathrm{Cu}-\mathrm{Cl}$, and $\mathrm{Cu}_{-} \mathrm{OH}_{2}$ are 1.998(5), 1.972(4), 2.271(3), and 2.278(5) $\AA$, respectively. Elongation of the $\mathrm{Cu}-\mathrm{OH}_{2}$ bond suggests a Jahn-Teller type distortion and leads to the formation of a distorted square pyramidal coordination geometry. The racemic mixture of the malate (D,L-malic acid) was utilized for UCuMal1 (Fig. 2a) and the single enantiomer (L-malic) for UCuMal2 (Fig. 2b), leading subtle differences in the chirality, but identical topological features.
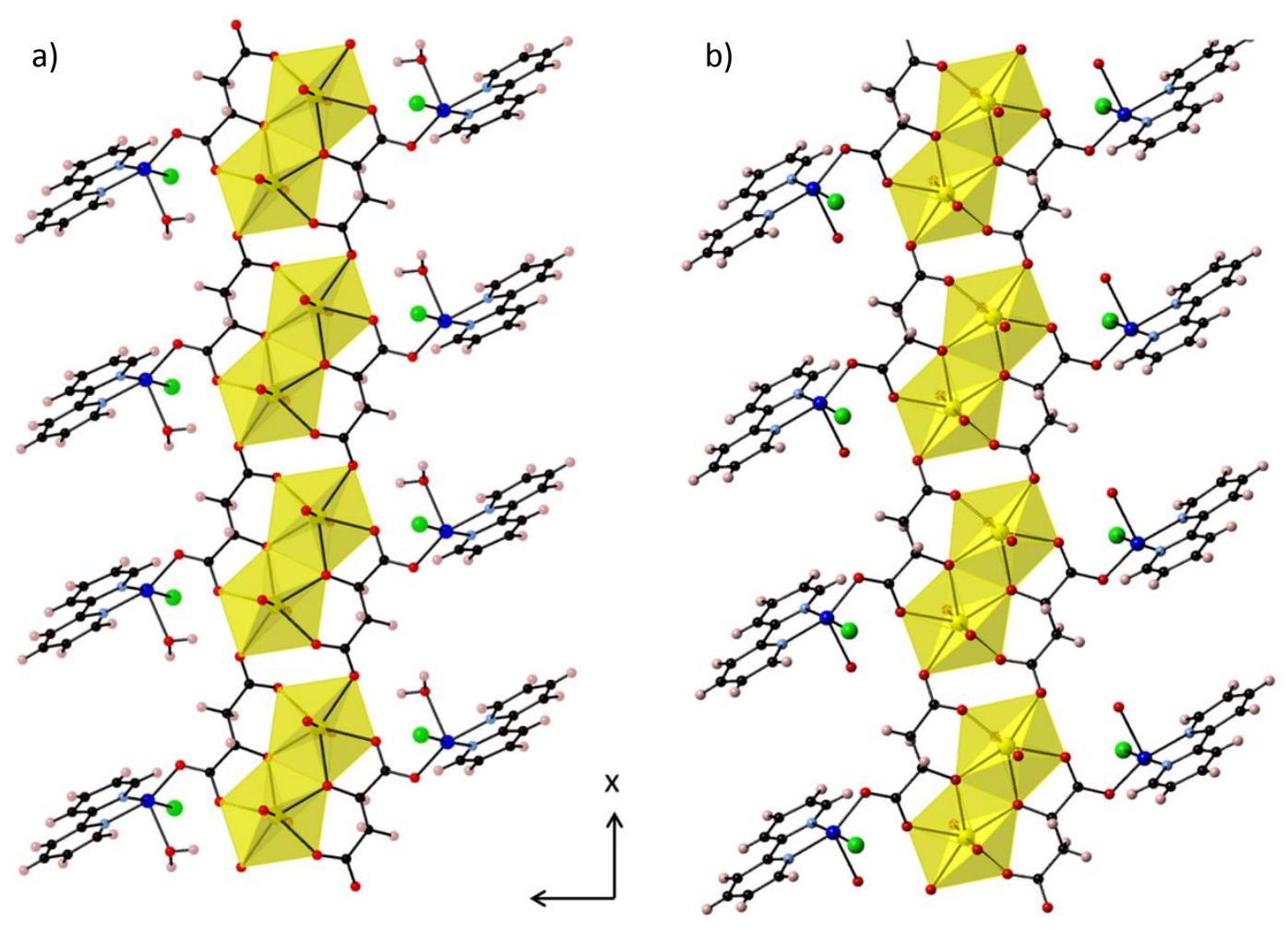

Figure 2. a) The dinuclear secondary building units are preserved in UCuMal1 (a) and UCuMal2 (b) and $\mathrm{Cu}(\mathrm{II})$ cations complexed by bipyridine, chlorine atoms and water molecules decorate the exterior of the chain. The racemic D,L-malate ligand is also observed in UCuMal1 whereas UCuMal2 crystallize with the L-malate enantiomer. U polyhedra are depicted in yellow and the $\mathrm{Cu}, \mathrm{Cl}, \mathrm{O}, \mathrm{C}, \mathrm{N}$, and $\mathrm{H}$ atoms are represented by dark blue, green, red, black, light blue and pink sphere, respectively. 
Due to the addition of the bipyridine ligand, additional intermolecular interactions occur between the neighboring chains, resulting in the crystallization of the material (Fig. 3). As shown in Figure 3 for the UCuMal1 compound, overlap of the bipyridine rings leads to $\pi-\pi$ interactions down the [001] direction. This interaction is also observed in UCuMal2 with average intermolecular distance between the bipyridine molecules of $4.47 \AA$. Interstitial water molecules are also observed in the lattice of both structures leading to the overall formula of $\left[\left(\mathrm{UO}_{2}\right)\left(\mathrm{D}, \mathrm{L}-\mathrm{C}_{4} \mathrm{H}_{3} \mathrm{O}_{5}\right) \mathrm{Cu}\left(\mathrm{C}_{10} \mathrm{H}_{8} \mathrm{~N}_{2}\right) \mathrm{Cl}\left(\mathrm{H}_{2} \mathrm{O}\right)\right]\left(\mathrm{H}_{2} \mathrm{O}\right)_{2}$ and $\left[\left(\mathrm{UO}_{2}\right)(\mathrm{L}-\right.$ $\left.\left.\mathrm{C}_{4} \mathrm{H}_{3} \mathrm{O}_{5}\right) \mathrm{Cu}\left(\mathrm{C}_{10} \mathrm{H}_{8} \mathrm{~N}_{2}\right) \mathrm{Cl}\left(\mathrm{H}_{2} \mathrm{O}\right)\right]\left(\mathrm{H}_{2} \mathrm{O}\right)_{2}$ for UCuMal1 and UCuMal2, respectively.

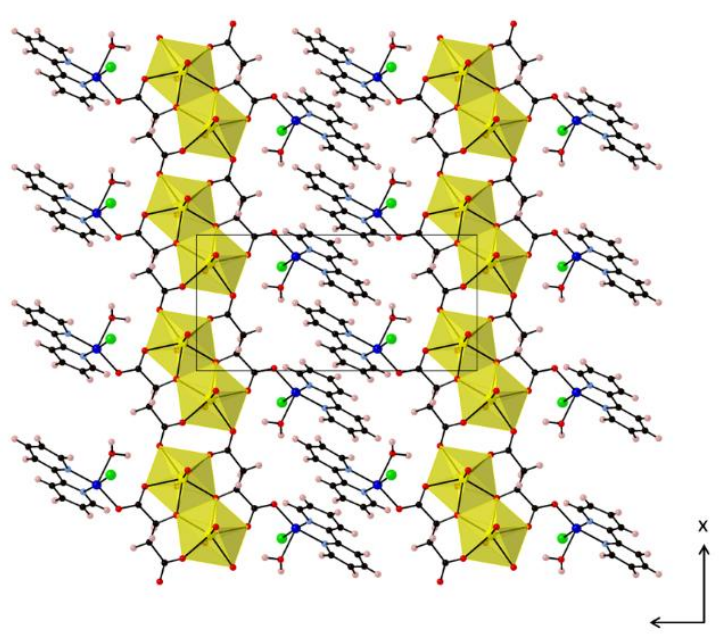

Figure 3. The uranyl copper malate coordination polymers in UCuMal1 and UCuMal2 interact through $\pi-\pi$ interactions between neighboring bipyridine molecules along the [001] direction.

Replacing the bipyridine ligand with pyridine molecules leads to a uranyl copper malate 2-D sheet topology for $\mathbf{U C u M a l 3 ~ ( F i g ~ 4 a ) . ~ T h e ~ u r a n y l ~ m a l a t e ~ c h a i n ~ t o p o l o g y ~ i s ~ c o n s e r v e d ~}$ within this compound, but additional polymerization occurs $\mathrm{Cu}(\mathrm{II})$ cation and the free carboxylate $\mathrm{O}$ atom of the neighboring chains, effectively serving serves as a bridge for the secondary building units. Interactions between the $\mathrm{Cu}(\mathrm{II})$ cation and the neighboring chains 
occurs in a trans-configuration with two additional pyridine molecules bonding to the metal center through the equatorial plane. The octahedral geometry about the $\mathrm{Cu}$ (II) cation is created upon bonding of two additional water molecules in the axial positions. Average $\mathrm{Cu}-\mathrm{N}$ and $\mathrm{Cu}-\mathrm{O}$ bond distances within the equatorial plane are 2.014(3) and 1.976(2) ^, respectively, but JahnTeller distortion causes elongation of the $\mathrm{Cu}-\mathrm{OH}_{2}$ bonds at 2.438(3) $\AA$. Due to steric constraints, the pyridine are not planar in relationship to the two-dimensional sheet and instead are canted $110^{\circ}$ from the plane and observed on the top and bottom of the sheet structure.
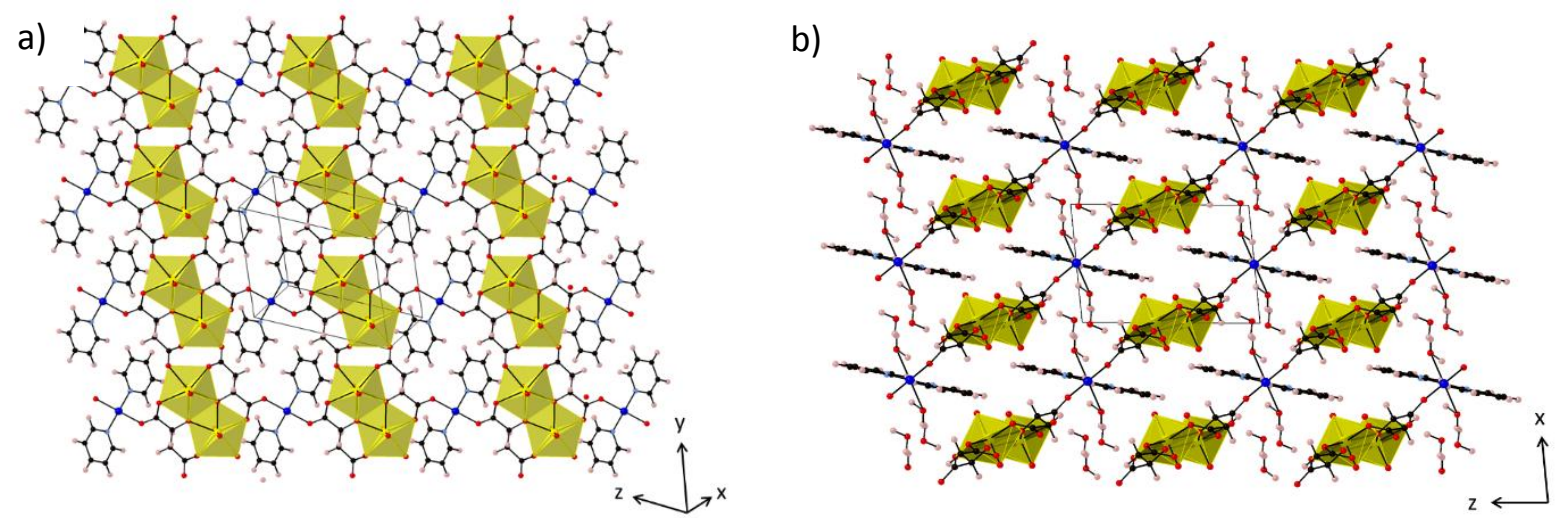

Figure 4. a) The bipyridine ligands are replaced by pyridine molecules in UCuMal3, resulting in the extension of the copper uranyl malate chain into a sheet topology. b) Ligated water molecules coordinated to the $\mathrm{Cu}$ (II) cation interact with neighboring interstitial water molecules through hydrogen bonding. $\mathrm{U}$ polyhedra are depicted in yellow and the $\mathrm{Cu}, \mathrm{Cl}, \mathrm{O}, \mathrm{C}, \mathrm{N}$, and $\mathrm{H}$ atoms are represented by dark blue, green, red, black, light blue and pink sphere, respectively.

UCuMal3 contains a two-dimensional topology that run parallel to the [202] plane and pack into a crystalline lattice through intermolecular interactions with intercalated solvent molecules (Fig. 4b). An additional water molecule (OW1) is located within the interstitial region and interacts through strong hydrogen bonds with the ligated water molecule with donor to acceptor distances of $2.86 \AA$. Addition of the solvent molecules leads to $\left[\left(\mathrm{UO}_{2}\right)_{2}\left(\mathrm{C}_{4} \mathrm{H}_{3} \mathrm{O}_{5}\right)_{2} \mathrm{Cu}\left(\mathrm{C}_{5} \mathrm{H}_{5} \mathrm{~N}\right)_{2}\left(\mathrm{H}_{2} \mathrm{O}\right)\right]\left(\mathrm{H}_{2} \mathrm{O}\right)$ as the overall formula of the $\mathbf{U C u M a l 3}$ compound. 
The coordination sphere of the $\mathrm{Cu}(\mathrm{II})$ cation has been shown to vary in hybrid bimetallic uranyl materials with either four, five, or six ligands bonding to the metal center to create square planar, square bipyramidal, or octahedral geometries. While square planar $\mathrm{Cu}(\mathrm{II})$ complexes are widely observed in coordination complexes, within hybrid bimetallic uranyl compounds, it has only been reported in $\left[\left(\mathrm{UO}_{2}\right)\left(\mathrm{H}_{2} \mathrm{O}\right)_{2}\left(\mathrm{C}_{7} \mathrm{H}_{3} \mathrm{NO}_{4}\right)_{2} \mathrm{Cu}\right]$ [28]. The square pyramidal coordination geometry observed in UCuMal1 and UCuMal2 is widely observed for both for compounds synthesized at room temperature and under hydrothermal conditions, but typically occurs in the presence of amines. Octahedral coordination spheres have also been observed, but significant elongation of the axial positions, resulting from $4+2$ Jahn-Teller distortions are observed, as is the case for both $\left.\left(\mathrm{Cu}\left(\mathrm{H}_{2} \mathrm{O}\right)_{2}\right)\left(\mathrm{UO}_{2}\right)_{4}\left[\mathrm{C}_{5} \mathrm{H}_{4} \mathrm{PO}_{3}\right)\left(\mathrm{C}_{6} \mathrm{H}_{4} \mathrm{PO}_{3} \mathrm{H}\right)\right]_{4}\left(\mathrm{C}_{8} \mathrm{H}_{6} \mathrm{~N}_{4}\right)[35]$ and $\left[\left(\mathrm{UO}_{2}\right)_{2} \mathrm{Cu}\left(\mathrm{C}_{10} \mathrm{H}_{16} \mathrm{O}_{4}\right)_{3}\left(\mathrm{C}_{5} \mathrm{H}_{9} \mathrm{NO}\right)_{2}\right][29]$.

Presence of transition metals can extend the dimensionality of uranyl hybrid materials, but choice of ligand is still the defining factor in determining the overall structural topology achieved in these systems. Without complexing ligands, the transition metal typically plays the role as a charge balancing cation intercalated between uranyl sheets [8]. Such is the case for the hexaqua- complexes of $\mathrm{Fe}(\mathrm{II}), \mathrm{Co}(\mathrm{II}), \mathrm{Ni}(\mathrm{II})$ and $\mathrm{Zn}(\mathrm{II})$ and hexamminecobalt(II) that have been incorporated into uranyl hybrid materials [16, 47-49]. Increasing the dimensionality for this system is more often achieved through additional coordination of the transition metal cation with free carboxylate groups. This interaction tends to favor the formation of framework topologies, particularly in when $\mathrm{Cu}(\mathrm{II}), \mathrm{Co}(\mathrm{II}), \mathrm{Mn}(\mathrm{II})$ cations are present in the uranyl-based compounds.

Direct interactions between the transition metal cation and the uranyl oxo group, also referred to in the actinide literature as a cation-cation interaction, is also observed in the formation of extended networks $[20,21,25]$. In some cases, these cation-cation interactions 
seem to be mediated by the organic ligands, as they provide additional chelation to stabilize the metal in this configuration [8]. In other cases, the metal itself seems to have a relatively strong interaction with the uranyl oxo group as evidenced by lengthening of the uranyl bond. This phenomenon can be observed in $\left[\left(\mathrm{UO}_{2}\right)_{2} \mathrm{O}(\mathrm{OH})_{2} \mathrm{Cu}\left(\mathrm{H}_{2} \mathrm{O}\right)_{2}\left(\mathrm{C}_{7} \mathrm{H}_{4} \mathrm{O}_{4}\right) \bullet \mathrm{H}_{2} \mathrm{O}\right.$, which displays

elongation of the uranyl bond length (1.805(3) $\AA$ ) and a smaller $\mathrm{Cu}-\mathrm{O}$ bond length $(2.350(3))$ compared to other copper uranyl hybrid materials that also display 4+2 Jahn-Teller distortion (bond lengths range from 2.43-2.74(5) $\AA$ ) [25]. The ability of the Cu(II) cation to undergo JahnTeller distortions is an important feature that provides additional interaction with the uranyl oxo and promotes dimensionality in the system.

\section{Thermogravimetric Analysis}

A small, initial weight loss occurred between 25 and $50^{\circ} \mathrm{C}$ for UMal1, followed by more significant decomposition of the material at $300{ }^{\circ} \mathrm{C}$ (Fig. 5). Dehydration of the solvent water molecules resulted in a weight loss of $5.27 \%$, which corresponds to 2.75 water molecules. This was slightly less than the four molecules predicted using single-crystal X-ray diffraction for UMal1, but the powder diffractogram suggested a small amount of the anhydrous UMal1-b compound that would account for the difference in hydration state (Fig. S1). Complete breakdown of the malate ligand and piperazinium cations resulted in a residual weight loss of 68.55\%. The PXRD diffractogram of the material after analysis, depicted a few broad peaks (Fig. S5), suggesting the formation of a poorly crystalline uranyl oxide or oxyhydroxide phase. 


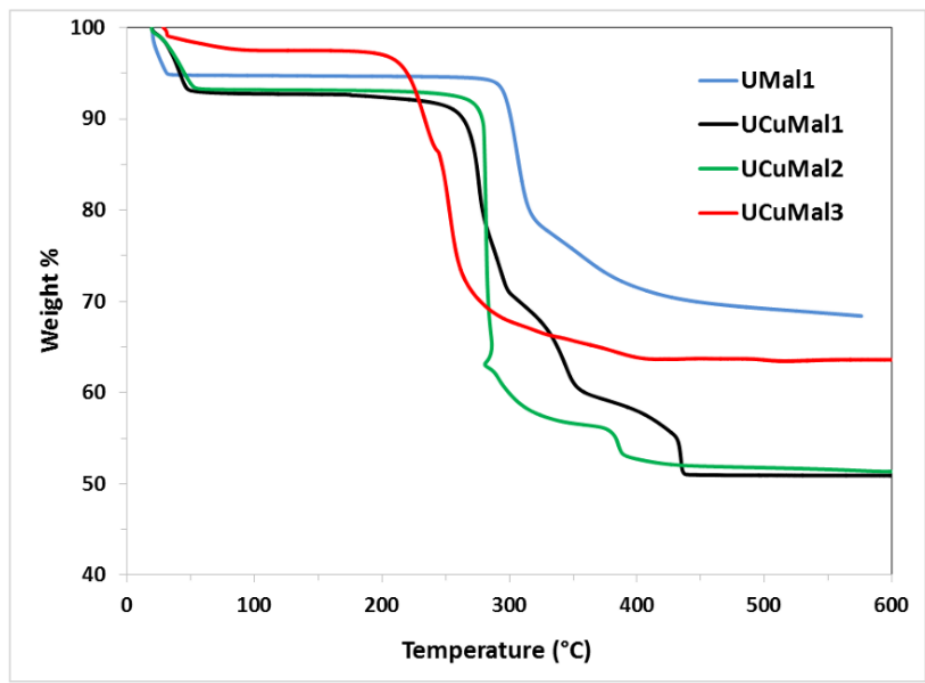

Figure 5. Thermogravimetric analysis of the UMal1, UCuMal1, UCuMal2, and UCuMal3 compounds.

The isostructural nature of UCuMal1 and UCuMal2 resulted in similar weight losses, with initial dehydration followed by removal of the organic components (Fig. 5). Dehydration was more gradual than the UMal compound because complete removal of the water occurs by 90 ${ }^{\circ} \mathrm{C}$. The dehydration step resulted in a $7.28 \%$ weight loss for both compounds, corresponding to the release of three water molecules per formula unit. This corresponds to removal of both the interstitial and ligated water molecules within the crystalline lattice, suggesting a weak $\mathrm{Cu}-\mathrm{OH}_{2}$ bond. A weak interaction between the $\mathrm{Cu}$ (II) cation and the axial $\mathrm{H}_{2} \mathrm{O}$ molecule is supported by the long average bond length of 2.278(5) A. Breakdown of the organic components was initiated at $245^{\circ} \mathrm{C}$ and occurs in three distinct steps. A final residual weight of $50 \%$ was observed for both compounds and identified as a mixture of $\mathrm{CuU}_{4} \mathrm{O}_{10}\left(\mathrm{PDF}\right.$ 00-044-0979), $\mathrm{CuUO}_{4}(\mathrm{PDF} 97-$ 003-6071), and $\mathrm{U}_{3} \mathrm{O}_{8}$ (PDF 97-019-1130) by PXRD.

Removal of the water in $\mathbf{U C u M a l 3}$ occurred between 25 and $95{ }^{\circ} \mathrm{C}$ and was followed by a significant weight loss at $250^{\circ} \mathrm{C}$ (Fig. 5). The initial weight loss was $2.53 \%$ and corresponds 
to 1.5 water molecules per formula unit. This could indicate the presence of some additional interstitial water molecules that were not observed with structural analysis or partial removal of the ligated water molecules attached to the $\mathrm{Cu}(\mathrm{II})$ cation. The large weight loss corresponds to the decomposition of the organic components and resulted in a residual weight of $63.5 \%$. Again the diffractogram identifies the decomposition product is a mixture of $\mathrm{CuU}_{4} \mathrm{O}_{10}$ (PDF 00-0440979), $\mathrm{CuUO}_{4}$ (PDF 97-003-6071), and $\mathrm{U}_{3} \mathrm{O}_{8}$ (PDF 97-019-1130) by PXRD.

\section{Vibrational Spectroscopy}

Major features of the Raman spectra for the uranyl malate and uranyl copper malate compounds wer found between 700 and $1100 \mathrm{~cm}^{-1}$. Figure 6 provides the combined spectra for this region for UMal1, UCuMal1, and UCuMal3. Spectra for UCuMal1 and UCuMal2 were identical; thus, only one spectrum is shown for clarity. The uranyl symmetric stretch $\left(v_{1}\right)$ is the strongest band in the spectra and occurs at 826,841 , and $833 \mathrm{~cm}^{-1}$ for UMal1, UCuMal1, and UCuMal3, respectively. The position of the symmetric stretching vibration is dependent on the variability of the orbital overlap for the ligands bonded through the equatorial plane to the $\mathrm{UO}_{2}{ }^{2+}$ cation. Addition of strong sigma donors lead to a red shift from the uranyl pentaaqua complex $\left(\left[\left(\mathrm{UO}_{2}\right)\left(\mathrm{H}_{2} \mathrm{O}\right)_{5}\right]^{2+}\right)$ band located at $870 \mathrm{~cm}^{-1}$ and the carboxylate groups of the malate ligand functions in this capacity [17]. All bands are blue shifted from the previously reported uranyl malate compounds, which observed a $v_{1}$ stretch at $816 \mathrm{~cm}^{-1}[41]$. In these molecular species, hydrolysis of the uranyl moiety leads to the formation of a trimer which has an additional $\mathrm{u}_{3}-\mathrm{O}$ group, leading to additional red shift of the symmetric stretching vibration [41]. 
Other strong bands observed in the Raman spectra corresponded to the malate ligand and the pyridine or 2,2-bipyridine molecules. Weaker secondary peaks in UMal1 are located at 785, 967 , and $1030 \mathrm{~cm}^{-1}$ and correspond to the malate ligand and piperazinium cations packed within the crystal structure. The peak positioned at approximately $790 \mathrm{~cm}^{-1}$ was also observed as a major band in the previously reported uranyl malate compounds [41]. Malate peaks are also

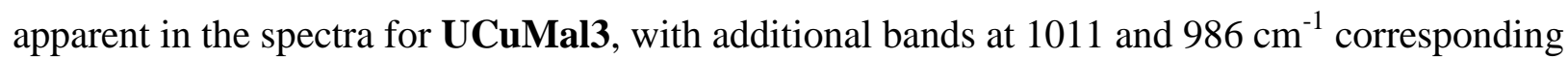
to the pyridine ligand. Peaks at 767, 806, 1030, and $1060 \mathrm{~cm}^{-1}$ are observed for UCuMal2 that represent the 2,2-bipyradine ligand complexed to the $\mathrm{Cu}(\mathrm{II})$ cation and the malate ligand.

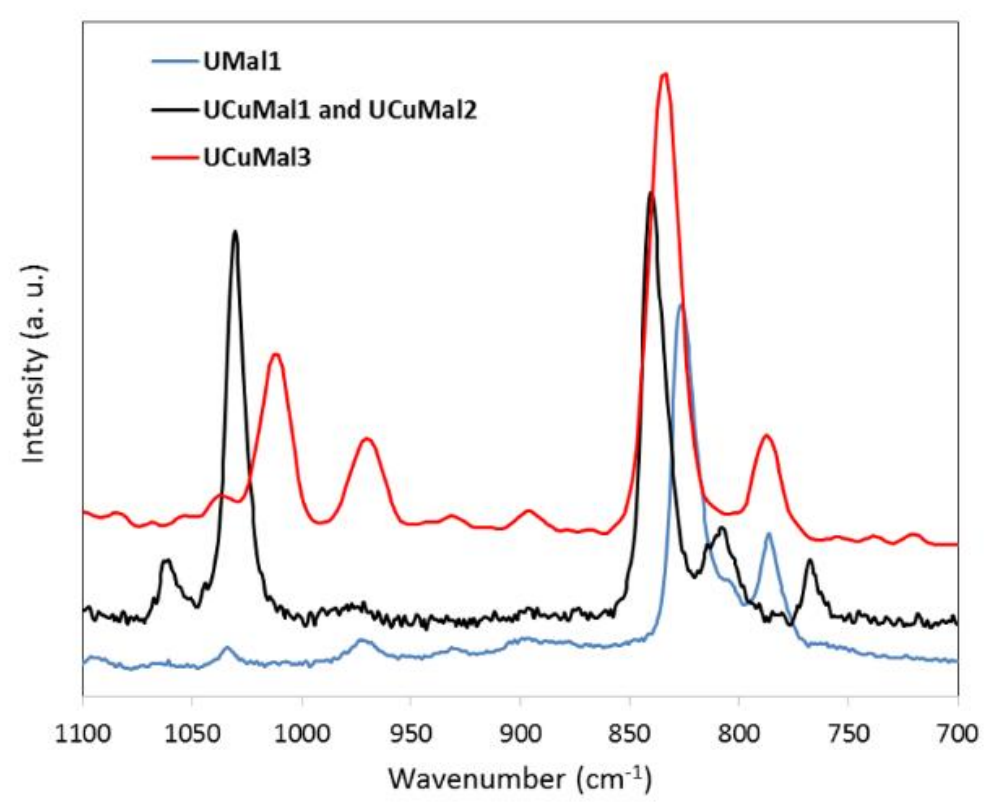

Figure 6. The Raman spectra for UMal1, UCuMal2, and UCuMal3.

\section{Conclusion}

Five uranyl malate compounds were synthesized, and characterized by single crystal X-ray diffraction, thermogravimetric analysis and Raman spectroscopy. The dinuclear uranyl malate secondary building unit was a dominate structural motif in all compounds, with additional 
variability observed through the addition of the $\mathrm{Cu}(\mathrm{II})$ cation. The presence of pyridine and bipyridine controlled the ability of the $\mathrm{Cu}$ (II) cation to complex to the neighboring uranyl malate chain, thus impacting the dimensionality of the system. Previously reported hybrid uranyl copper compounds exhibited additional extension in dimensionality through the presence of cation-cation interactions between the uranyl oxo group and the $\mathrm{Cu}$ (II) cation. Chemical characterization confirmed the structural model for these compounds and overall this system demonstrates the important structural features in the design of dimensionality within uranyl hybrid materials.

\section{Acknowledgements}

We would like to acknowledge the National Science Foundation Division of Materials Research (DMR 1252831) for funding this work. In addition, we thank the University of Iowa Diffraction facility for use of the powder diffractometer and the Central Microscopy Facility for use of the Raman spectrophotometer. 


\section{References}

[1] G. Desiraju, J. Am. Chem. Soc., 135 (2013) 9952.

[2] M. Du, C.-P. Li, C.-S. Liu, S.-M. Fang, Coord. Chem. Rev., 257 (2013) 1282.

[3] A.M. Kirillov, Coord. Chem. Rev., 255 (2011) 1603.

[4] C.B. Aakeroy, N.R. Champness, C. Janiak, Crystengcomm, 12 (2010) 22.

[5] G. Desiraju, J.J. Vittal, A. Ramanan, Crystal Engineering: A Textbook, World Scientific Phblishing Company, Singapore, 2011.

[6] P.C. Burns, The Can. Mineral., 43 (2005) 1839.

[7] M.B. Andrews, C.L. Cahill, Chem. Rev., 113 (2013) 1121.

[8] T. Loiseau, I. Mihalcea, N. Henry, C. Volkringer, Coord. Chem. Rev., 266-267 (2014) 69.

[9] K.-X. Wang, J.-S. Chen, Acc. Chem. Res., 44 (2011) 531.

[10] S. Berto, F. Crea, P.G. Daniele, A. Gianguzza, A. Pettignano, S. Sammartano, Coord. Chem. Rev., 256 (2012) 63.

[11] K.E. Knope, L. Soderholm, Chem. Rev., 113 (2013) 944.

[12] M.B. Andrews, C.L. Cahill, Dalton Trans., 41 (2012) 3911.

[13] A. Clearfield, K. Demadis, Metal Phosphonate Chemistry: From Synthesis to Applications., The Royal Society of Chemistry, London, 2012.

[14] N.P. Deifel, C.L. Cahill, Compt. Rend. Chim., 13 (2010) 747.

[15] N.P. Deifel, C.L. Cahill, Crystengcomm, 11 (2009) 2739.

[16] A.N. Alsobrook, B.G. Hauser, J.T. Hupp, E.V. Aekseev, W. Depmeier, T.E. Albrecht-Schmitt, Cryst. Growth Des., 11 (2011) 1385.

[17] S. Fortier, T.W. Hayton, Coord. Chem. Rev., 254 (2010) 197.

[18] C.L. Cahill, D.T. de Lill, M. Frisch, CrystEngComm, 9 (2007) 15.

[19] P. Thuery, CrystEngcomm, 9 (2007) 358.

[20] A.N. Alsobrook, W. Zhan, T.E. Albrecht-Schmitt, Inorg. Chem., 47 (2008) 5177.

[21] P. Thuery, Inorg. Chem. Comm., 12 (2009) 800.

[22] M. Frisch, C.L. Cahill, Dalton Trans., (2005) 1518.

[23] P. Thuery, Inorg. Chem., 52 (2013) 435.

[24] P.O. Adelani, T.E. Albrecht-Schmitt, Cryst. Growth Des., 11 (2011) 4676.

[25] J. Olchowka, C. Falaise, C. Volkringer, N. Henry, T. Loiseau, Chem. -Eur. J., 19 (2012) 2012.

[26] L. Liang, Y. Cia, X. Li, R. Zhang, J. Zhao, C. Liu, N.S. Weng, Z. Anorg. Allge. Chem., 641 (2015) 1744.

[27] Z. Weng, Z.-h. Zhang, T. Olds, M. Sterniczuk, P.C. Burns, Inorg. Chem., 53 (2014) 7993.

[28] A.T. Kerr, C.L. Cahill, Cryst. Growth Des, 14 (2014) 4094.

[29] P. Thuery, J. Harrowfield, Crystengcomm, 16 (2014) 2996.

[30] P. Thuery, E. Riviere, Dalton Trans., 42 (2013) 10551. 
[31] P. Thuery, Cryst. Growth Des., 14 (2014) 2665.

[32] D.K. Unruh, K. Gojdas, A. Libo, T.Z. Forbes, J. Am. Chem. Soc., 135 (2013) 7398.

[33] G.A. Senchyk, E.M. Wylie, S. Prizio, J.E.S. Szymanowski, G.E. Sigmon, P.C. Burns, Chem. Comm., 51 (2015) 10134.

[34] P. Thuery, Cryst. Growth Des.,14 (2014) 901.

[35] P.O. Adelani, N.D. Cook, J.-M. Babo, P.C. Burns, Inorg. Chem., 53 (2014) 4169.

[36] J. Ling, F. Hobbs, S. Prendegast, P.O. Adelani, J.M. Babo, J. Qiu, Z. Weng, P.C. Burns, Inorg. Chem., 24 (2014) 12877.

[37] R.W.W. Hoft, in: B.V. Nonius (Ed.), Delft, The Netherlands, 1998.

[38] G.M. Sheldrick, in, Bruker AXS, Madison, WI, 1996.

[39] G.M. Sheldrick, Acta Cryst. Sect. A: Found. Cryst., 64 (2008).

[40] A.L. Spek, in, Utrecht University, Utrecht, The Netherlands, 2005.

[41] D.K. Unruh, K. Gojdas, E. Flores, A. Libo, T.Z. Forbes, Inorg. Chem., 52 (2013) 10191.

[42] P. Thuery, CrystEngComm, 15 (2013) 2401.

[43] P. Thuery, Inorg. Chem., 46 (2007) 2307.

[44] M.B. Andrews, C.L. Cahill, Crystengcomm, 13 (2011) 7068.

[45] L. Duvieubourg, G. Nowogrocki, F. Abraham, S. Grandjean, J. Sol. State Chem., 178 (2005) $3437-$ 3444.

[46] P. Thuery, Acta Cryst. Sect. C: Cryst. Struct. Comm., C64 (2008) m50.

[47] A.N. Alsobrook, E.V. Alekseev, W. Depmeier, T.E. Albrecht-Schmitt, Cryst. Growth Des., (2011) 2358.

[48] A. Zalkin, H. Ruben, D.H. Templeton, Acta Cryst.. Sect. B-Struct. Comm., B38 (1982) 610.

[49] K.E. Knope, C.L. Cahill, Eur. J.Inorg. Chem., 2010 (2010) 1177. 

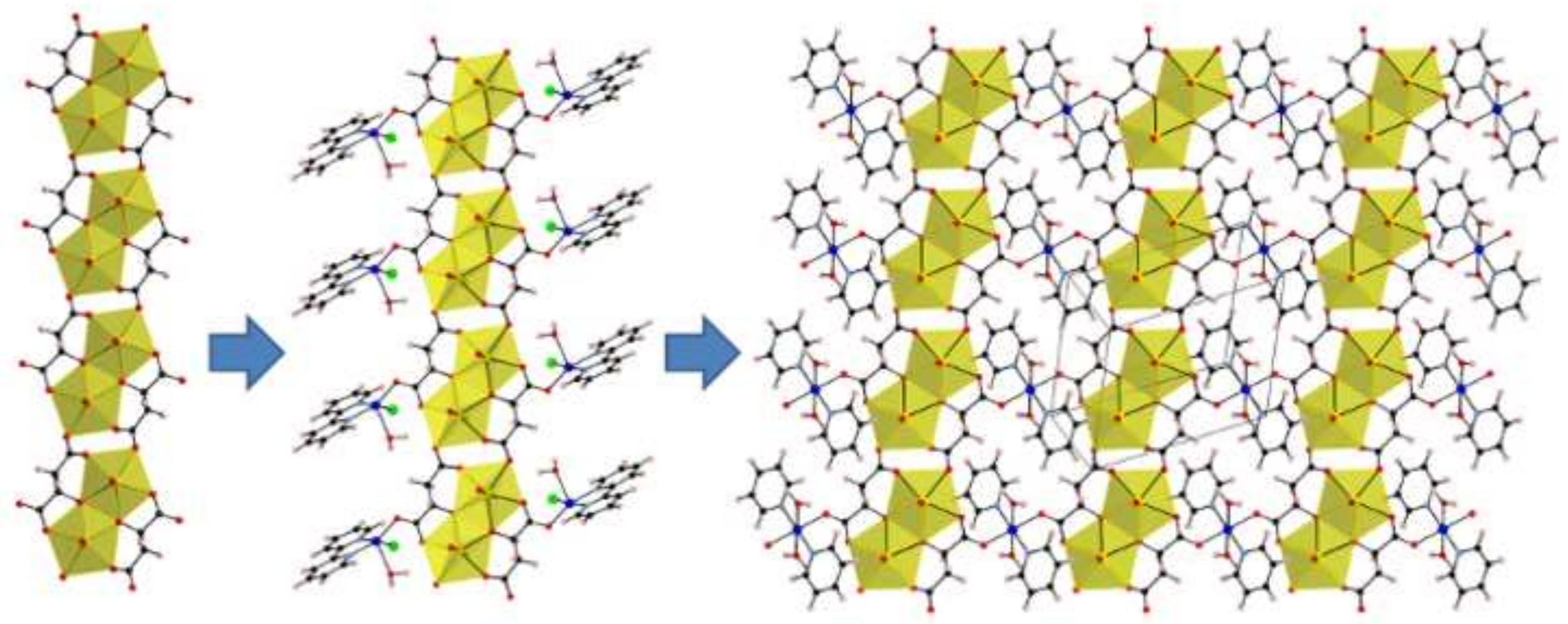